\title{
PENGARUH TERAPI MUSIK TERHADAP PENURUNAN PERILAKU AGRESI PADA REMAJA
}

\author{
Yosephine $^{1}$, Monty P. Satiadarma ${ }^{2}$ dan Yohana Theresia ${ }^{3}$ \\ ${ }^{1}$ Fakultas Psikologi, Universitas Tarumanagara, Jakarta \\ Email: yosephine.717171014@stu.untar.ac.id \\ ${ }^{2}$ Fakultas Psikologi, Univeristas Tarumanagara, Jakarta \\ Email: montys@fpsi.untar.ac.id \\ ${ }^{3}$ Fakultas Psikologi, Universitas Tarumanagara, Jakarta \\ Email: hana.sheva@gmail.com
}

Masuk : 17-04-2019, revisi: 25-11-2019 diterima untuk diterbitkan : 26-11-2019

\begin{abstract}
ABSTRAK
Buss (dalam Baron \& Richardson, 2004) mengatakan bahwa perilaku agresi merupakan sebuah tindakan yang bertujuan untuk menyakiti orang lain. Perilaku agresi paling tinggi berada pada masa perkembangan remaja, khususnya pada usia 14 sampai dengan 18 tahun (Farrel et al., 2005; Karriker-Jaffe, Foshee, Ennett, \& Suchindran, 2009). Terapi musik merupakan proses penyembuhan yang menggunakan media musik untuk memenuhi kebutuhan fisik, emosional, kognitif, dan sosial pada individu di segala umur (AMTA, 2005). Terapi musik diprediksi dapat menurunkan perilaku agresi pada remaja, terbukti dari berbagai penelitian terdahulu. Tujuan penelitian ini adalah untuk mengetahui pengaruh terapi musik terhadap penurunan perilaku agresi pada remaja di Jakarta. Pada penelitian ini, peneliti menyertakan 30 siswa di SMA X, Jakarta dengan menggunakan teknik purposive-criterion sampling dan quota sampling. Partisipan dibagi menjadi 3 kelompok, yaitu (a) kelompok terapi musik aktif, (b) kelompok terapi musik pasif, dan (c) kelompok kontrol. Desain penelitian adalah true experiment dengan three-group pretest-posttest, yang menganalisis data dengan Uji ANOVA. Hasil penelitian menunjukkan terapi musik dapat menurunkan perilaku agresi secara signifikan $(p<0.05)$. Hal tersebut menunjukkan bahwa baik terapi musik aktif maupun terapi musik pasif dapat diterapkan untuk menurunkan perilaku agresi pada remaja.
\end{abstract}

Kata Kunci: musik, terapi musik, agresi, remaja

\begin{abstract}
Buss (in Baron \& Richardson, 2004) says that aggressive behavior is an action that aims to hurt others. The highest aggression behavior is occur when the adolescence developed itself time to time, especially at ages 14 to 18 years (Farrel et al., 2005; Karriker-Jaffe, Foshee, Ennett, \& Suchindram, 2009). Music therapy is a healing process that uses music media to meet physical, emotional, cognitive, and social needs in individuals of all ages (AMTA, 2005). Music therapy is predicted can be reduce aggressive behavior in adolescence, as evidenced by various previous studies. The purpose of this research is to determine the result of the decreasing aggressive behavior toward the adolescence in Jakarta. In this study, researchers included 30 students at SMA X, Jakarta using purposive-ciretrion sampling and quota sampling techniques. Participants were divided into 3 groups, and the groups are; (a) active music therapy group, (b) passive music therapy group, and (c) control group. The design of this experiment is using a true experiment with three-group pretest-posttest, which analyzes data with ANOVA test. The results showed that music therapy can significantly reduce aggressive behavior ( $p<0.05)$. This shows that both active music therapy and passive music therapy can be applied to reduce aggressive behavior in adolescence.
\end{abstract}

Keywords: music, therapy music, aggressive behavior, adolescence.

\section{PENDAHULUAN \\ Latar Belakang}

Tahapan perkembangan remaja merupakan masa pencarian jati diri yang ditandai dengan ketidakstabilan emosi. Remaja sering kali mudah terpicu emosinya atau mudah tersinggung. Hal tersebut menyebabkan remaja tidak dapat beradaptasi dengan lingkungan, sehingga menunjukkan perilaku maladaptif, yang salah satunya merupakan perilaku agresi (Santrock, 2012). Buss (dalam Baron \& Richardson, 2004) mendefinisikan agresi sebagai perilaku yang disengaja atau tidak disengaja yang dapat melukai orang lain. Raine et al. (2006) mengatakan bahwa agresi terdiri dari reactive aggression dan proactive aggression. Reactive aggression merupakan tindakan 
memusuhi, impulsif, dan tidak terencana yang sering disertai dengan marah karena adanya dorongan otonom dan kehilangan kontrol impuls (Bushman \& Anderson, 2001; Collins, 2016; Scarpa, Haden, \& Tanaka, 2010), karena adanya provokasi (Crick \& Dodge, dalam Gao et al., 2015; Raine et al., 2006) yang sering kali diasosiasikan dengan emosi, kecemasan dan kemarahan (Dodge \& Coie, dalam Euler, Steinlin, \& Stadler, 2017). Sedangkan, proactive aggression merupakan tindakan yang bertujuan untuk menguasai atau mendominasi objek atau orang lain, tanpa adanya provokasi (Vitaro et al., dalam Collins, 2016).

Perilaku agresi bersifat age-normative pada individu yang berada pada kelompok usia anak-anak dan remaja. Hal tersebut menandakan bahwa pada kelompok usia anak-anak dan remaja merupakan kelompok usia yang paling sering memunculkan perilaku agresi. Pada usia remaja, perilaku agresi menjadi lebih merugikan karena memiliki prevalensi senjata api dan senjata lainnya (Baumeister, Bushman, \& Campbell, 2000). Pada usia 14 tahun, individu mengalami peningkatan yang signifikan dalam perilaku agresi, usia 17 tahun dan 18 tahun merupakan usia dengan perilaku agresi tertinggi. Setelah usia 18 tahun, tingkat perilaku agresi mengalami penurunan (Farrel et al., 2005; Karriker-Jaffe, Foshee, Ennett, \& Suchindran, 2009). Perilaku agresi pada remaja sering kali dikaitkan dengan perilaku menyimpang atau kenakalan remaja (Sarwono, 2012). Perilaku agresi siswa di sekolah sudah menjadi masalah yang universal. Berita mengenai terlibatnya para siswa dalam berbagai bentuk kerusuhan, tawuran, perkelahian, dan tindak kekerasan lainnya semakin sering terdengar (Ma'ruf, 2015).

Berdasarkan data Badan Pusat Statistik [BPS], pada tahun 2013 terdapat sebanyak 6.325 kasus kenakalan remaja, kemudian pada tahun 2014, terdapat sebanyak 7.007 kasus kenakalan remaja. Selanjutnya, pada tahun 2015, kembali mengalami peningkatan, menjadi sebanyak 7.762 kasus kenakalan remaja (BPS, 2016). Berdasarkan dari data yang didapatkan, diketahui bahwa setiap tahunnya terjadi peningkatan jumlah kenakalan remaja. Peningkatan tersebut tentunya perlu ditanggulangi agar tidak semakin meningkat.

Terdapat beragam intervensi yang dapat menanggulangi perilaku agresi, yaitu art therapy (Alavinezhad, Mousavi, \& Sohrabi, 2014), behavioral therapy (Sukhodolsky et al., 2016), cognitive-behavior therapy (Chen et al., 2014; Sukhodolsky, Kassinove, \& Gorman, 2004), rational-emotive behavior therapy yang diiringi dengan cogntive-behavior therapy (Obiagaeri, 2018), dan music therapy (Choi, Lee, \& Lee, 2010; Dobryńska, Cesarz, Rymaszewska, \& Kiejna, 2006; Gholami, Bshlideh, \& Rafiei, 2013; Montello \& Coons, 1998; Nöcker-Ribaupierre \& Wölfl, 2010; Rickson \& Watskin, 2003; Tonarelli, 2016).

Keterlibatan musik dalam terapi dapat menjadi pilihan yang baik, karena musik dekat dengan remaja. Hal tersebut terlihat dari fenomena remaja cenderung menghabiskan waktunya dengan menonton video musik atau mendengarkan musik (Davis, Gfeller, \& Thaut, 1999). Manusia, khususnya remaja, diketahui sering kali mendengarkan musik dan menggunakan musik untuk mengekspresikan pemikiran, perasaan, dan dapat dilakukan untuk treatment, penyembuhan, serta mendapatkan sensasi ketenangan (Ebneshahidi \& Mohseni, 2008). Musik merupakan sebuah hal yang penting bagi remaja dan dapat memiliki pengaruh yang besar sebagai media terapeutik untuk diterapkan kepada individu yang berada pada tahapan remaja (Davis, Gfeller, \& Thaut, 1999).

Terapi musik terbagi menjadi 3 jenis, yaitu (a) terapi musik pasif atau guided music listening with counseling, partisipan akan diminta untuk mendengarkan lagu yang sudah ditentukan oleh peneliti, namun partisipan juga dapat memilih lagu sesuai preferensi musiknya, kemudian mendiskusikan pengalaman atau perasaan selama sesi berlangsung; (b) terapi musik pasif dengan relaksasi, 
partisipan diminta untuk melakukan kegiatan relaksasi, progressive muscle relaxation, dan diiringi oleh lagu yang sudah ditentukan oleh peneliti, kemudian mendiskusikan pengalaman atau perasaan selama sesi berlangsung; (c) terapi musik aktif, partisipan akan terlibat aktif dalam aktivitas musik, seperti menyanyi, memainkan alat musik, dan membuat improvisasi (Davis, Gfeller, \& Thaut, 1999; Thaut, 1989; Yinger, 2017).

Rea, MacDonald, dan Carnes (2010) melakukan perbandingan efek atau dampak musik klasik, pop, dan musik heavy metal terhadap manusia. Hasil penelitian menemukan bahwa individu yang mendengarkan lagu bergenre heavy metal cenderung merasa tegang dan cemas. Sedangkan, individu yang mendengarkan lagu pop dan klasik menjadi lebih tenang, nyaman, dan tingkat kecemasan berkurang. Berdasarkan beberapa penelitian di atas menunjukkan hasil yang beragam mengenai korelasi antara genre musik yang berperan sebagai terapi kepada perilaku agresi. Namun, mayoritas pada penelitian di atas dapat terlihat bahwa musik yang lebih santai seperti klasik mempunyai hasil yang konsisten dalam mengurangi perilaku agresi seseorang.

Tempo juga dinilai memiliki peranan penting dalam pemilihan lagu untuk terapi musik. Satiadarma (2002) mengatakan dalam memilih lagu, perlu mempertimbangkan ritme dalam lagu, karena ritme musik yang didengarkan dapat terintegrasi dengan ritme internal manusia. Ritme lambat dalam musik dapat membuat pendengar merasa tenang (Satiadarma, 2002). Ritme dalam sebuah musik dapat memicu tubuh untuk menyesuaikan fungsi fisiologis manusia, seperti detak jantung, tekanan darah, dan pernafasan sehingga selaras dengan ritme musik yang didengar. Ritme musik ditemukan dapat membantu individu untuk mengendalikan impuls, mengikuti aturan, dan menimbulkan perasaan aman dan nyaman (Bruscia, dalam Montello \& Coons, 1998).

Pada penelitian ini, terdapat dua rumusan masalah, yaitu:

1. Bagaimana pengaruh terapi musik terhadap penurunan perilaku agresif pada remaja?

2. Apakah ada beda antara terapi musik aktif dan terapi musik pasif dalam penurunan perilaku agresif pada remaja?

\section{METODE PENELITIAN}

\section{Partisipan dan prosedur penelitian}

Prosedur pengambilan data pada penelitian ini diawali dengan melakukan tahapan screening untuk mendapatkan partisipan yang sesuai berdasarkan purposive-criterion sampling dan quota sampling. Partisipan awal pada penelitian ini terdiri dari 138 siswa SMA X, Jakarta. Setelah melalui tahapan screening, didapatkan 30 siswa yang memenuhi kriteria penelitian. Seluruh partisipan intervensi merupakan siswa kelas 10, 11, dan 12 yang terdiri dari 13 partisipan berjenis kelamin perempuan dan 17 partisipan berjenis kelamin laki-laki. Rentang partisipan dari 15 tahun sampai dengan 18 tahun $(\mathrm{M}=16.37, \mathrm{SD}=0.999)$.

Prosedur penelitian yang dilakukan adalah melakukan pretest dan posttest menggunakan alat ukur RPQ dan TRF yang akan diberikan sebelum dan sesudah perlakukan intervensi sebanyak 6 sesi. 30 partisipan akan dibagi menjadi 3 kelompok, yaitu kelompok terapi musik aktif (A), kelompok terapi musik pasif (P), dan kelompok Kontrol (K). Pada kelompok A, partisipan akan terlibat aktif dalam memainkan alat musik dan bernyanyi. Sedangkan, pada kelompok P, partisipan akan diminta untuk mendengarkan musik yang sudah didiskusikan sebelum intervensi dimulai sesuai dengan preferensi musik para partisipan. Peneliti akan membandingkan hasil pretest dan posttest untuk mengetahui signifikansi pengaruh terapi musik terhadap perilaku agresi pada remaja. Kelompok A akan diminta untuk terlibat aktif dalam aktivitas musik, yaitu group naming, menyuarakan detak jantung, membuat irama dari benda sekitar, memainkan musik dengan alat 
musik yang dikuasai, dan membuat improvisasi musik. Kelompok $\mathrm{P}$ akan diminta untuk mendengarkan musik-musik yang sudah ditentukan dan disepakati bersama. Sedangkan, kelompok K tidak mendapat perlakuan apa pun.

\section{Pengukuran/ instrumen penelitian}

Pada penelitian ini, peneliti menggunakan 2 buah alat ukur, yaitu Reactive-Proactive Aggression Questionnaire [RPQ] yang dikembangkan oleh Raine et al. (2006) dan Teacher's Report Form [TRF] yang dikembangkan oleh Achenbach dan Edelbrock pada tahun 1983. RPQ terdiri dari 23 butir pernyataan, yang terdiri dari 11 butir pernyataan yang mengukur reactive aggression dan 12 butir pernyataan yang mengukur proactive aggression. Contoh butir reactive aggression adalah "membentak orang lain ketika mereka membuat Anda kesal", sedangkan contoh butir proactive aggression adalah berkelahi antar kelompok agar terlihat keren. Skala yang digunakan pada RPQ adalah skala likert, yang terdiri dari 0 (tidak pernah), 1 (kadang-kadang), dan 2 (sering). Alat ukur ini memiliki reliabilitas yang baik, yaitu memiliki alpha cronbach sebesar 0.81 untuk reacitve aggression, 0.84 untuk proactive aggression, dan 0.89 untuk total aggression. Alat ukur ini juga dilakukan beberapa uji validitas. Pertama, uji convergent validity, hasil total skor RPQ menunjukkan adanya hubungan yang signifikan terhadap perilaku agresi, angry-irritability, dan simtom agresi (Collins, 2016). Proactive aggression memiliki hubungan yang signifikan dengan deliquency scale. Sedangkan reactive aggression memiliki hubungan yang signifikan positif dengan self-report hostility-aggression scale (Raine et al., 2006).

Kedua, criterion validity, seluruh skor RPQ menunjukkan hubungan yang signifikan negatif dengan prosocial behavior dan signifikan positif dengan depresi, cemas, keinginan bunuh diri, permasalahan sosial, substance abuse disorder, dan conduct disorder (Collins, 2016). Berdasarkan uji criterion validity menunjukkan bahwa skor dimensi reactive aggression memiliki hubungan yang signifikan negatif dengan violent strong-arm tactics, namun skor dimensi proactive aggression memiliki hubungan yang signifikan postif dengan violent strong-arm tactics. Seluruh skor RPQ memiliki hubungan positif terhadap memulai perkelahian, sering terlibat dalam perkelahian, serta kejahatan atau pelanggaran yang serius (Raine et al., 2006). Ketiga, discriminant validity, menunjukkan bahwa tidak terdapat hubungan signifikan dengan withdrawal, somatic complaints, thought problems, dan social problems (Raine et al., 2006). Berdasarkan dari hasil pengujian validitas, alat ukur RPQ dapat dikatakan valid karena memiliki hasil yang baik setelah diuji dengan menggunakan convergent validity, criterion validity, serta discriminant validty.

Peneliti mengadaptasi alat ukur RPQ dari bahasa Inggris ke bahasa Indonesia yang dibantu oleh penerjemah tersumpah. Peneliti melakukan pengujian content validity melalui meminta bantuan 3 (tiga) ahli untuk melakukan expert judgment. Peneliti meminta pengujian validitas isi kepada Dr. Monty P. Satiadarma, MS/AT, MCP/MFCC, DCH, Psi., Dr. Fransisca I. R. Dewi, M. Si., dan Yohana Theresia, M.Psi., Psi. Setelah itu, peneliti melakukan pengujian alat ukur terhadap 284 partisipan dengan rentang usia 14 sampai dengan 18 tahun untuk menguji konsistensi atau reliabilitas pada alat ukur yang sudah diadaptasi oleh peneliti. Hasil dari pengujian validitas dan reliabilitas pada alat ukur perilaku agresi, secara keseluruhan, dari total 23 butir pada alat ukur RPQ, tidak ada butir yang perlu dieliminasi karena tidak valid atau tidak reliabel untuk mengukur perilaku agresi. 
Tabel 1. Hasil Uji reliabilitas Alat Ukur RPQ

\begin{tabular}{ccc}
\hline Dimensi $\boldsymbol{R P Q}$ & Jumlah Butir & Alpha Cronbach \\
\hline Proactive Aggression & 12 & 0.758 \\
Reactive Aggression & 11 & 0.825 \\
Total Aggression & 23 & 0.870 \\
\hline
\end{tabular}

Pada dimensi proactive aggression dan reactive aggression dapat dikatakan valid dan reliabel. Peneliti mengatakan hal tersebut karena skor corrected item-total correlation dari tiap butirnya lebih besar dari pada 0,2 dan skor alpha cronbach pada dimensi proactive aggression adalah 0,735 dan dimensi reactive aggression adalah 0,820. Untuk lebih jelasnya, dapat dilihat pada tabel 1 .

TRF merupakan alat ukur yang dapat digunakan untuk anak usia 6 tahun sampai dengan 18 tahun yang terdiri dari 113 butir pernyataan, yang mengukur 6 indikator perilaku, yaitu a) menarik diri, (b) keluhan somatis, (c) kecemasan, (d) problem sosial, (e) problem berpikir , (f) problem perhatian, (g) perilaku delikuensi, dan (h) perilaku agresi. Skala yang digunakan adalah skala likert, yang terdiri dari 0 (tidak sesuai), 1 (sesuai), dan 2 (sangat sesuai). Butir pada TRF seluruhnya merupakan butir positif (Achenbach, 1991a; Yuanita, Jatnika, \& Susianti, 1999). Pada penelitian ini, peneliti juga hanya menggunakan item-item yang mengukur mengenai perilaku agresi. Hal tersebut dikarenakan peneliti hanya mengukur perilaku agresi yang dimiliki oleh partisipan. Perilaku agresi yang diukur pada TRF terdiri dari 25 item berdasarkan persepsi guru terhadap muridnya yang berkaitan dengan perhatian, motivasi, dan sikap bermusuhan (Achenbach, 1991a).

Contoh butir dari dimensi perilaku agresi pada alat ukur TRF adalah menuntut banyak perhatian dan merusak barang orang lain. TRF memiliki reliabilitas yang baik. Hasil pengujian reliabilitas pada dimensi perilaku agresi, alpha cronbach yang didapat sebesar 0.8413 dan split half dengan koreksi Spearman-Brown sebesar 0.8085. Berdasarkan angka yang didapat, dapat dikatakan bahwa TRF yang sudah dialih bahasa ke bahasa Indonesia sudah baik atau reliabel karena di atas 0.7. Berdasarkan hasil pengembangan alat ukur yang dilakukan oleh Yuanita, Jatnika, dan Susianti (1999), terdapat 6 item yang perlu dieliminasi sehingga menjadi 17 item. Pada alat ukur TRF ini, peneliti juga melakukan pengujian content validity kepada 3 (tiga) ahli yang sama, yaitu Dr. Monty P. Satiadarma, MS/AT, MCP/MFCC, DCH, Psi., Dr. Fransisca I. R. Dewi, M. Si., dan Yohana Theresia, M.Psi. untuk melakukan expert judgement. Hasil dari pengujian content validity pada alat ukur TRF, secara keseluruhan, dari total 17 item setelah dieliminasi berdasarkan hasil pengembangan alat ukur yang dilakukan oleh Yuanita, Jatnika, dan Susianti (1999), tidak ada butir yang perlu diperbaiki atau dieliminasi karena kurang sesuai atau tidak valid untuk mengukur perilaku agresi.

\section{HASIL DAN PEMBAHASAN}

Berdasarkan hasil pengujian One Way ANOVA pada penurunan skor perilaku agresi, diketahui bahwa data yang didapatkan berdasarkan kuesioner RPQ terdistribusi normal, namun data bersifat heterogen (tidak homogen). Hal tersebut menentukan bahwa peneliti akan menguji hipotesis menggunakan uji univariate One Way ANOVA, yaitu pengaruh terapi musik terhadap penurunan perilaku agresi. Hasil uji F ANOVA dikoreksi berdasarkan uji Brown-Forsythe atau Welch's F karena asumsi homogenitas tidak terpenuhi. Berdasarkan hasil uji One Way ANOVA, nilai F hitung sebesar 28.021 dengan nilai $p$ lebih kecil dari pada 0.05, dengan demikian H0 ditolak $\mathrm{H} 1$ diterima. Maka, dapat disimpulkan bahwa berdasarkan alat ukur RPQ terapi musik berpengaruh secara signifikan terhadap penurunan perilaku agresi pada remaja. Berdasarkan hasil uji BrownForsythe dan Welch's F untuk koreksi hasil uji F ANOVA karena data tidak homogen, 
menunjukkan bahwa nilai $p$ lebih kecil dari pada 0.05 , maka dapat dikatakan diterima $\mathrm{H} 1$ yang berarti intervensi terapi musik memberikan perbedaan yang signifikan terhadap penurunan perilaku agresi berdasarkan alat ukur RPQ. Besarnya pengaruh intervensi terhadap penurunan perilaku agresi berdasarkan alat ukur RPQ adalah sebesar adjusted $R$ square yaitu 0.651 atau $65.1 \%$.

Berdasarkan hasil pengujian di atas, diketahui bahwa data yang didapatkan berdasarkan kuesioner TRF terdistribusi normal dan bersifat homogen, maka pengujian hipotesis menggunakan uji univariate One Way ANOVA, yaitu pengaruh terapi musik terhadap penurunan perilaku agresi pada remaja. Berdasarkan hasil uji One Way ANOVA, nilai F hitung sebesar 11.579 dengan nilai $p$ lebih kecil dari pada 0.05, dengan demikian $\mathrm{H}_{0}$ ditolak $\mathrm{H} 1$ diterima. Maka, dapat disimpulkan bahwa berdasarkan alat ukur TRF terapi musik berpengaruh secara signifikan terhadap penurunan perilaku agresi pada remaja. Peneliti mengatakan hal tersebut karena besarnya pengaruh intervensi terhadap penurunan perilaku agresi berdasarkan alat ukur RPQ adalah sebesar adjusted $R$ square yaitu 0.422 atau $42.2 \%$. untuk keterangan lebih detail, dapat dilihat pada tabel 2 .

Tabel 2. Hasil Uji One Way ANOVA Penurunan Skor Perilaku Agresi

\begin{tabular}{cccc}
\hline Alat Ukur & $\boldsymbol{F}$ & Sig. & Adjusted $\boldsymbol{R}$ Squared \\
\hline RPQ & 28.021 & 0.000 & 0.651 \\
TRF & 11.578 & 0.000 & 0.422 \\
\hline
\end{tabular}

Setelah mengetahui bahwa terapi musik memiliki pengaruh yang signifikan terhadap penurunan perilaku agresi pada remaja, peneliti ingin menguji signifikasi perbedaan antar kelompok. Peneliti melakukan uji post hoc dengan uji Games Howell karena data RPQ yang didapat tidak bersifat homogen. Berdasarkan hasil uji Games Howell, diketahui bahwa besaran nilai mean difference antara kelompok terapi musik pasif dan terapi musik aktif berdasarkan alat ukur RPQ sebesar 3.300 dengan nilai $p$ lebih besar dari pada 0.05, dengan demikian, $\mathrm{H} 0$ ditolak dan $\mathrm{H} 1$ diterima. Maka, dapat dikatakan bahwa tidak terdapat perbedaan signifikan antara penurunan perilaku agresi pada kelompok terapi musik pasif dan terapi musik aktif. Besaran nilai mean difference antara kelompok terapi musik pasif dan kelompok kontrol berdasarkan alat ukur RPQ sebesar -6.000 dengan nilai $p$ lebih kecil dari pada 0.05. Maka, dapat dikatakan bahwa terdapat perbedaan signifikan antara penurunan perilaku agresi pada kelompok terapi musik pasif dengan kelompok kontrol. Hal yang serupa juga didapatkan pada perbandingan antara kelompok terapi musik aktif dan kelompok kontrol. Besaran nilai mean difference antara kelompok terapi musik pasif dan kelompok kontrol berdasarkan alat ukur RPQ sebesar -9.300 dengan nilai $p$ lebih kecil dari pada 0.05. Maka, dapat dikatakan bahwa terdapat perbedaan signifikan antara penurunan perilaku agresi pada kelompok terapi musik aktif dan kelompok kontrol.

Peneliti juga menguji post hoc pada alat ukur TRF. Peneliti melakukan uji post hoc dengan uji Bonferroni karena data yang didapatkan dari alat ukur TRF bersifat homogen. Berdasarkan uji Bonferroni, diketahui bahwa besaran mean difference antara kelompok terapi musik pasif dengan terapi musik aktif adalah 2.500 dengan nilai $p$ lebih besar dari pada 0.05. Maka, dapat dikatakan bahwa tidak terdapat perbedaan signifikan antara penurunan perilaku agresi pada kelompok terapi musik pasif dan terapi musik aktif. Sedangkan, jika dibandingkan dengan kelompok kontrol, peneliti menemukan hasil yang berbeda. Besaran nilai mean difference antara kelompok terapi dan musik pasif dengan kelompok kontrol adalah sebesar -4.100 dengan nilai $p$ lebih kecil dari pada 0.05. Maka, dapat dikatakan bahwa terdapat perbedaan signifikan antara hasil penurunan perilaku agresi pada kelompok terapi musik pasif dengan kelompok kontrol. Hal serupa juga ditemukan pada perbandingan dengan kelompok terapi musik aktif. Besaran mean difference antara kelompok terapi musik aktif dengan kelompok kontrol adalah sebesar -6.600 dengan nilai $p$ lebih kecil dari 
pada 0.05. Maka, dapat dikatakan terdapat perbedaan signifikan antara kelompok terapi musik aktif dengan kelompok kontrol.

Berdasarkan pemaparan di atas, dapat disimpulkan bahwa baik dari alat ukur RPQ maupun TRF, H1 diterima. Maka, tidak ada beda signifikan antara hasil penurunan perilaku agresi pada kelompok terapi pasif dan kelompok terapi aktif. Perbedaan signifikan hanya terdapat antara hasil penurunan perilaku agresi pada kelompok terapi pasif dengan kelompok kontrol serta kelompok terapi aktif dengan kelompok kontrol. Untuk lebih detail, dapat dilihat pada tabel 3.

Tabel 3. Hasil Perbandingan Selisih Posttest dengan Pretest Antar Kelompok

\begin{tabular}{ccccc}
\hline \multirow{2}{*}{ Kelompok } & \multicolumn{2}{c}{ RPQ } & \multicolumn{2}{c}{ TRF } \\
\cline { 2 - 5 } & Mean Difference & Sig. & Mean Difference & Sig. \\
\hline Pasif \& Aktif & 3.300 & 0.102 & 2.500 & -.247 \\
Pasif \& Kontrol & -6.000 & 0.000 & -4.100 & 0.019 \\
Aktif \& Kontrol & -9.300 & 0.000 & -6.600 & 0.000 \\
\hline
\end{tabular}

Setelah mengetahui bahwa terapi musik memiliki pengaruh yang signifikan terhadap penurunan perilaku agresi pada remaja, namun tidak ada perbedaan yang signifikan antara kelompok terapi musik aktif dengan terapi musik pasif, peneliti ingin mengetahui jenis terapi yang lebih efektif dalam menurunkan perilaku agresi ditinjau dari rerata selisih antara posttest dengan pretest. Berdasarkan perbandingan selisih antara posttest dengan pretest dari setiap kelompok, diketahui estimasi nilai rerata terendah, yang berarti paling banyak mengalami penurunan adalah kelompok terapi musik aktif. Kelompok terapi musik aktif memiliki mean selisih antara posttest dan pretest paling besar, yaitu sebesar -8.400. Kelompok terapi musik pasif menempati nomor urut 2 paling banyak penurunannya yaitu dengan nilai rerata sebesar -5.100. Sedangkan, kelompok kontrol merupakan kelompok yang paling sedikit penurunannya karena cenderung mengalami kenaikan pada perbandingan posttest dengan pretest yaitu nilai rerata sebesar 0.900 .

Jika ditinjau dari alat ukur TRF, perbandingan selisih antara posttest dengan pretest dari setiap kelompok, diketahui bahwa estimasi nilai rerata terendah, yang berarti paling banyak mengalami penurunan adalah kelompok terapi musik aktif. Kelompok terapi musik aktif memiliki mean selisih antara posttest dengan pretest sebesar -6.400. Kelompok terapi musik pasif menempati nomor urut 2 paling banyak penurunannya, yaitu dengan nilai rerata sebesar -3.900. Sedangkan, kelompok kontrol merupakan kelompok yang paling sedikit penurunannya karena cenderung mengalami kenaikan pada perbandingan antara posttest dengan pretest, yaitu memiliki nilai rerata sebesar 0.200. Untuk lebih detail, dapat dilihat pada tabel 4.

Tabel 4. Hasil Perbandingan Selisih Posttest dengan Pretest Antar Kelompok

\begin{tabular}{ccccc}
\hline \multirow{2}{*}{ Kelompok } & \multicolumn{2}{c}{$\boldsymbol{R P Q}$} & \multicolumn{2}{c}{ TRF } \\
\cline { 2 - 5 } & Mean & Std. Error & Mean & Std. Error \\
\hline Pasif & -5.100 & 0.891 & -3.900 & 0.979 \\
Aktif & -8.400 & 0.891 & -6.400 & 0.979 \\
Kontrol & 0.900 & 0.891 & 0.200 & 0.979 \\
\hline
\end{tabular}

Berdasarkan hasil analisis data menunjukkan bahwa adanya penurunan yang signifikan pada perilaku agresi dengan pemberian intervensi terapi musik. Hal tersebut sejalan dengan penelitian yang dilakukan oleh beberapa penelitian terdahulu, yaitu penelitian yang dilakukan oleh Choi, Lee, \& Lee (2010) serta Rickson \& Watkin (2003) meneliti mengenai terapi musik aktif, Gholami, Bshlideh, dan Rafiei (2013) serta Tonarelli (2016) yang meneliti mengenai terapi musik pasif. 
Serta, Montello dan Coon (1998) yang meneliti mengenai perpaduan antara terapi musik aktif dan pasif. Seluruh penelitian tersebut menemukan hal yang serupa dengan hasil penelitian peneliti, yaitu terdapat pengaruh yang signifikan pada penurunan perilaku agresi dengan pemberian intervensi terapi musik.

Walaupun tidak terdapat perbedaan yang signifikan antara pengaruh terapi musik aktif dan pasif terhadap perilaku agresi pada remaja, diketahui bahwa terapi musik aktif memiliki mean penurunan perilaku agresi yang lebih tinggi dibandingkan dengan terapi musik pasif. Hal tersebut sesuai dengan hasil penelitian yang dilakukan oleh Montello \& Coons (1998) yang menemukan bahwa baik terapi musik aktif maupun pasif efektif untuk menurunkan perilaku agresi dan hostility. Namun, Montello dan Coons (1998) menemukan hal yang serupa bahwa penurunan perilaku agresi, actiong out, dan conduct disorder mengalami penurunan yang lebih setelah partisipan melakukan terapi musik aktif. Bermain musik secara ritmis dapat mengontrol energi menjadi lebih terstruktur. Hal tersebut membantu partisipan untuk meningkatkan self-control serta menyesuaikan diri dengan anggota kelompok lain. Terapi musik aktif dapat membantu partisipan untuk mengeksplorasi perasaan negatif (benci atau marah) di dalam lingkungan yang terasa aman dalam sebuah kelompok.

Berdasarkan hasil kegiatan terapi musik pasif, diketahui bahwa tidak hanya tempo dalam musik yang diperdengarkan yang perlu dipertimbangkan, namun juga lirik dari lagu. Gladding (2005) menemukan musik menjadi bermakna bagi individu karena lirik musik tersebut memiliki keterkaitan dengan pribadi dari pendengarnya, misalnya pengalaman hidup. Selain itu, individu juga mempertimbangkan lirik sebagai pesan yang dapat disampaikan dan dihayati, serta lirik lagu juga dapat memunculkan perasaan tenang atau gembira pada individu yang mendengarkannya. Musik yang didengar tidak perlu harus lagu yang dianggap familiar, namun musik yang didengar perlu memiliki lirik yang bermakna atau membahas mengenai topik yang membangkitkan respons emosional.

Gladding, Newsome, Binkley, dan Henderson (2008) mengatakan bahwa menggunakan lagu berlirik pada konseling efektif digunakan untuk membangkitkan respons emosional yang terpendam pada partisipan. Lagu berlirik dapat digunakan untuk mengekspresikan emosi, mengedukasi anggota kelompok, memunculkan empati, menanggulangi stres, dan menginspirasi pendengar lagu tersebut (Buser et al., 2005; Hendricks \& Bradley, 2005).

Seperti halnya penelitian yang dilakukan oleh Tonarelli (2016) serta Montello dan Coons (1998), partisipan pada kelompok terapi musik pasif dapat memilih lagu yang ingin diperdengarkan pada sesi terapi berlangsung. Berdasarkan partisipan intervensi, partisipan cenderung memilih lagu berdasarkan preferensi musik partisipan. Maka, pemilihan lagu tidak dapat sama pada setiap penelitian. Pemilihan lagu pada terapi musik pasif dapat berubah-ubah tergantung dari partisipan penelitian. Sehingga, terapi musik dapat dikatakan bersifat situasional atau sesuai perkembangan zaman berdasarkan popularitas musik saat pelaksanaan intervensi.

\section{KESIMPULAN DAN SARAN}

Hasil analisis data yang telah dilakukan mengenai pengaruh terapi musik terhadap penurunan perilaku agresi menunjukkan adanya penurunan yang signifikan ditinjau dari hasil perbandingan pretest dan posttest dari partisipan penelitian. Tidak terdapat perbedaan signifikan antara penggunaan terapi musik pasif ataupun terapi musik aktif dalam menurunkan perilaku agresi pada remaja. Namun, berdasarkan perbandingan rerata selisih pretest dan posttest baik alat ukur RPQ 
$(\mathrm{F}=28.021, p<0.005)$ dengan besar pengaruh sebesar 65.1\% maupun TRF $(\mathrm{F}=11.578, p<0.05)$ dengan besar pengaruh sebesar $42.2 \%$.

Berdasarkan pengujian post hoc, diketahui bahwa tidak ada perbedaan signifikan antara perbandingan hasil penurunan perilaku agresi antara terapi musik aktif dengan terapi musik pasif $(p>0.05)$. Jika ditinjau dari perbandingan rerata selisih posttest dengan pretest pada partisipan intervensi, diketahui bahwa urutan selisih dari yang tertinggi adalah sebagai berikut. Pertama, terapi musik aktif memiliki nilai rerata selisih perbedaan yang paling besar, yaitu -8.400 berdasarkan alat ukur RPQ dan -6.400 berdasarkan alat ukur TRF. Kedua, terapi musik pasif memiliki nilai rerata selisih sebesar -5.100 berdasarkan alat ukur RPQ dan -3.900 berdasarkan alat ukur TRF. Ketiga, kelompok kontrol memiliki nilai rerata selisih terendah yaitu sebesar 0.900 berdasarkan alat ukur RPQ dan 0.200 berdasarkan alat ukur TRF.

Disarankan untuk penelitian selanjutnya agar memperluas rentang partisipan menjadi usia 11 sampai dengan 19 tahun sehingga dapat mengetahui lebih mendalam mengenai pengaruh terapi musik pada remaja. Penelitian terapi musik juga dapat tidak hanya terbatas pada tahapan perkembangan remaja, namun dapat diaplikasikan kepada masa kanak-kanak atau dewasa. Sehingga, peneliti juga menyarankan untuk penelitian selanjutnya agar mencoba intervensi terapi musik kepada partisipan yang berada pada tahapan perkembangan selain remaja. Hal tersebut dilakukan agar dapat memperluas cakupan rentang usia untuk dapat menerapkan terapi musik terhadap penurunan perilaku agresi. Saran yang ingin peneliti berikan kepada praktisi adalah dalam melakukan pemilihan musik yang akan diberikan kepada partisipan perlu mempertimbangkan mengenai preferensi musik masing-masing partisipan. Namun, praktisi tetap harus mempertimbangkan genre, tempo dan instrumen yang digunakan dalam musik tersebut. Saran yang ingin peneliti berikan kepada pihak sekolah, khususnya kepala sekolah dan guru-guru sekolah. Berdasarkan hasil penelitian yang menyatakan bahwa terapi musik memiliki pengaruh signifikan untuk menurunkan perilaku agresi, maka disarankan untuk mempertimbangkan menggunakan terapi musik untuk mengatasi siswa SMA yang diindikasi memiliki perilaku agresi. Sehingga, perilaku agresi yang dimiliki oleh siswa dapat ditanggulangi dengan baik. Selain itu, peneliti menyarankan pihak sekolah untuk mengantisipasi dengan pengawasan serta memberikan tindakan seperti penyuluhan, menyarankan untuk mengikuti ekstrakurikuler musik, serta aktivitas lain yang berkaitan dengan musik.

\section{Ucapan Terima Kasih (Acknowledgement)}

Peneliti mengucapkan terima kasih yang sebesar-besarnya kepada pihak-pihak yang telah berkontribusi dalam penyelesaian dan penyusunan penelitian ini. Terima kasih kepada Dr. Monty P. Satiadarma, MS/AT, MCP/MFCC, DCH, Psikolog dan Yohana Theresia, M.Psi., Psikolog yang telah dengan sabar membimbing peneliti. Peneliti juga mengucapkan terima kasih kepada SMA X atas izin yang diberikan untuk melakukan penelitian dan seluruh siswa yang menjadi partisipan penelitian yang selalu mengikuti proses intervensi dengan antusias dan sangat kooperatif.

\section{REFERENSI}

Achenbach, T. M. (1991a). Manual for the youth self-report and 1991 profile. Burlington, VT: University of Vermont.

Alavinezhad, R, Mousavi, M., \& Sohrabi, N. (2014). Effect of art therapy on anger and self-esteem in aggressive children. Elvesier, 113, 111-117, www.sciencedirect.com

American Music Therapy Association. (2005). Definition of music therapy. musictherapy.org Badan Pusat Statistik. (2016). Statistik Indonesia. bps.go.id

Baron, R. A. \& Richardson, D. R. (2004). Human aggression. New York: Plenum Press. 
Baumeister, R. F., Bushman, B. J., \& Campbell, W. K. (2000). Self-esteem, narcissism, and aggression: Does violence result from low self-esteem or from threatened egotism? Current Directions in Psychological Bulletin, 9, 26-29.

Buser, T., Flannery, B., Bentley, P., \& Gladding, S. (2005). The impact of musical lyrics on the lives of graduate counseling students. Journal of Creativity in Mental Health, 1(2), 81-92. doi:10.1300/J456v01n02_08

Bushman, B. J. \& Anderson, C. A. (2001). Is it time to pull the plug on the hostile versus instrumental aggrssion dichotomy? Psychological Review, 108, 273-279.

Chen, C., Li, C., Wang, H., Ou, J, Zhou, J., \& Wang, X. (2014). Cognitive behavioural therapy to reduce overt aggression behavior in chinese young male violent offenders. Aggressive Behavior, 40, 329-336. pdfs.semanticscholar.org

Choi, A., Lee, M., \& Lee, J. (2010). Group music intervention reduces aggression and improves self-esteem in children with highly aggressive behavior: A pilot controlled trial. EvidenceBased Complementary \& Alternative Medicine (Ecam), 7(2), 213-217. doi: 10.1093/ecam/nem182

Collins, O. F. (2016). Assessing reactive and proactive aggression in detained adolescents outside of a research context. Children Psychiatry Human Development, 47, 159-172. Doi: $10.1007 / \mathrm{s} 10578-015-0553-\mathrm{z}$

Davis, W. B., Gfeller, K. E., \& Thaut, M H. (1999). An introduction to music therapy: Theory and practice (2nd ed.). USA: McGraw-Hill.

Dobryńska, E., Cesarz, H., Rymaszewska, J., \& Kiejna, A. (2006). Music therapy: History, definitions and application. Archives of Psychoatry and Psychotherapy, 8(1), 47-52. https://www.researchgate.net/publication/282647747

Ebneshahidi, A. \& Mohseni, M. (2008). The effect of patient-selected music on early postoperative pain, anxiety, and hemodynamic profile in cesarean section surgery. Journal of Alternative and Complementary Medicine, 14(7), 827-831. Doi: 10.1089/acm.2007.0752

Euler, F., Steinlin, C., \& Stadler, C. (2017). Distinct profiles of reactive and proactive aggression in adolescents: Associations with cognitive and affective empathy. Children Adolescent Psychiatry Mental Health, 11(1), 1-14

Farrel, A. D., Sullivan, T. N., Esposito, L. E., Meyer, A. L., \& Valois, R. F. (2005). A latent growth curva analysis of the structure of aggression, drug use, and delinquent behaviors and their interrelations over time in urban and rural adolescents. Journal of Research on Adolescence, 15(2), 179-177. Doi: 10.1111/j.1532-7795.2005.00091.x

Gao, Y., Tuvblad, C., Schell, A., Baker, L., \& Raine, A. (2015). Skin conductance fear conditioning impairements and aggression: A longitudinal study. Psychophysiology, 52(2), 288-295

Gholami, A., Bshlideh, K., \& Rafiei, A. (2013). The impact of two methods of music therapy and relaxation on the aggression in high school students. Journal Of Jahrom University of Medical Sciences, 11(2), 7-12.

Gladding, S. T., Newsome, D., Binkley, E., \& Henderson, D. (2008). The lyrics of hurting and healing: Finding words that are revealing. Journal of Creativity in Mental Health, 3(3), 212219. doi:10.1080/15401380802385210

Hendricks, C. B., \& Bradley, L. J. (2005). Interpersonal theory and music techniques: A case study for a family with a depressed adolescent. The Family Journal: Counseling and Therapy for Couples and Families, 13, 400-405. doi:10.1177/ 1066480705278469

Karriker, K. J., Foshee, V. A., Ennett, S. T., \& Suchindran, C. (2009). The development of aggression during adolescence: Sex differences in trajectories of physical and social aggression amoung youth in rural areas. Journal of abnormal Child Psychology, 36(8), 1227-1236. Doi: 10.1007/s10802-008-9245-5 
Ma'ruf, H. (2015). Perilaku agresi relasi siswa di sekolah. Yogyakarta: Aswaja Pressindo.

Montello, L., \& Coons, E. E. (1998). Effects of active versus passive group music therapy on preadolescents with emotional, learning, and behavioral disorders. Journal Of Music Therapy, 35(1), 49-67.

Nöcker-Ribaupierre, M., \& Wölfl, A. (2010). Music to counter violence: a preventative approach for working with adolescents in schools. Nordic Journal Of Music Therapy, 19(2), 151-161. doi:10.1080/08098131.2010.489997

Obiagaeri, E. R. (2018). Efficacy of rational emotive behavioural therapy and cognitive behavior therapy in reducing aggressive behavior among secondary school students in Abia State. Internasional Journal of Humanities Social Sciences and Education, 5(1), 77-82. arcjournals.org

Raine, A., Dodge, K., Loeber, R., Gatzke-Kopp, L., Lynam, D., Reynolds, C., Stouthamer-Loeber, M., \& Liu, J. (2006). The reactive-proactive aggression questionnaire: Differential correlated of reactive and proactive aggression in adolescent boys. Aggressive Behavior, 32(2), 159-171. Doi:10.1002/ab/20115

Rea, C., MacDonald, P., \& Caners, G. (2010). Listening to classical, pop, and metal music: An investigation of mood. Emporia State Reasearch Studies, 46(1), 1-3. academic.emporia.edu.

Rickson, D. J., \& Watkins, W. G. (2003). Music Therapy to promote prosocial behaviors in aggressive adolescent boys - A pilot study. Journal Of Music Therapy, 40(4), 283-301. doi:10.1093/jmt/40.4.283

Santrock, J. W. (2012). Life-span development: Perkembangan masa-hidup (13 ${ }^{\text {th }}$ ed.) (N. I. Sallama, Ed.). Indonesia: Erlangga.

Sarwono, S. W. (2012). Pengantar psikologi umum (4th ed.) (E. A. Meinarno, Ed.). Jakarta: PT Rajagrafindo Persada.

Satiadarma, M. P. (2002). Terapi musik. Jakarta: Milenia Populer.

Scarpa, A., Haden, S. C., \& Tanaka, A. (2010). Being hot-tempered: Autonomoc, emotional, and behavioral distinctions between childhood reactive and proactive aggression. Biological Psychology, 84(3), 488-498. doi:10.1016/j.biopsycho.2009.11.006.

Sukhodolsky, D. G., Kassinove, H., \& Gorman, B. S. (2004). Cognitive-behavioural therapy for anger in children and adolescents: A meta-analysis. Aggressive Violent Behavior, 9(247), 247-269. sciencedirect.com

Sukhodolsky, D. G., Smoth, S. D., McCauley, S. A., Ibrahim, K., \& Piasecka, J. D. (2016). Behavioral interventions for anger, irritability, and aggression in children and adolescents. Journal of Child and Adolescent Psychopharmacology, 26(1), 58-64. Doi: 10.1089/cap.2015.0120

Thaut, M. H. (1989). The influence of music therapy interventions on self-rated changes in relaxation, affect, and thought in psychiatric prisoner-patients. Journal of Music Therapy, 26, 155-166.

Tonarelli, L. (2016). Bathing with music helps reduce aggression. Nurse Aide-VIP, 28(9), 12.

Yinger, O. S. (2017). Music therapy: Research and evidence-based practice. doi: 10.1016/c20160-01352-9

Yuanita, R. A., Jatnika, A., \& Susiati, E. (1999). Pengembangan alat ukur TRF: Laporan penelitian. Inspektoral Jendral Departemen Koperasi, Indonesia. 